\title{
Informed consent for upper gastrointestinal endoscopy
}

\author{
S P Pereira, S H Hussaini, M L Wilkinson
}

\begin{abstract}
Informed consent for upper gastrointestinal endoscopy requires that the patient understands the nature of, and reason for, the proposed procedure, and that he or she is given adequate time to deliberate and ask questions. In a prospective study, 200 outpatients completed questionnaires immediately before, and one day after, endoscopy, which assessed satisfaction with information provided by: (a) the referring doctor, (b) a standard information sheet sent out two to four weeks before endoscopy, and (c) the endoscopist. The first 100 patients were asked to read and sign a standard consent form immediately before the endoscopy. In the second 100 patients, a new endoscopy consent form that was simpler and easier to read than the standard form was sent out with the information sheet. Patients were directed to sign the new consent form before arriving at the unit only if they had no further questions. Overall, the indication for the endoscopy, and how it would be done, were explained clearly by the referring doctor in $79 \%$ and $68 \%$ of cases, respectively. Of the first 100 patients, only $54 \%$ had read the standard consent form in the endoscopy unit before signing it. In contrast, of the second 100 patients, the new form sent with the information sheet was read by $95 \%$, and signed by $88 \%$ before coming to the unit. Furthermore, $84 \%$ found the new form easier to read and understand than the standard form. In our unit, roughly one quarter of patients referred for endoscopy are not adequately informed about the procedure. In contrast with the standard consent form, a simple endoscopy consent form sent out with the information sheet is preferred by most patients, and safeguards against patients undergoing endoscopy without informed consent. (Gut 1995; 37: 151-153)
\end{abstract}

Keywords: gastrointestinal endoscopy, informed consent.

Gastrointestinal endoscopists obtain informed consent on a daily basis. Appropriate information may initially be provided to patients by the referring doctor or through a written information sheet, but the endoscopist must also ensure that patients understand the nature of, and reason for, the proposed procedure, as well as its risks and complications.

The aims of this study were, firstly, to determine what proportion of patients referred to the endoscopy unit of a London teaching hospital, are given sufficient information before upper gastrointestinal endoscopy so as to satisfy the criteria of informed consent. ${ }^{1}$ Secondly, as the provision of a home consent form and information sheet has been shown to improve patients' knowledge in other clinical settings, ${ }^{23}$ we designed a simple endoscopy consent form that was sent out with the endoscopy information sheet, and assessed patients' acceptance of a new consent form signing procedure.

\section{Subjects and methods}

Two hundred outpatients referred for diagnostic upper gastrointestinal endoscopy, were surveyed prospectively. ${ }^{4}$ Patients were asked to complete an initial questionnaire while in the endoscopy waiting room, which assessed (on five step nominal scales) the quality of information provided by the referring doctor concerning the indication for endoscopy, and how it would be done. The patients were also asked how helpful the standard information sheet (sent out to patients two to four weeks beforehand) had been in explaining the endoscopy, and whether they still had any questions about the procedure. A second questionnaire, filled out the day after the endoscopy, assessed the quality of information provided by the endoscopist.

\section{Consent forms}

In the first 100 patients, a signed consent was obtained in the usual manner. With the patient sitting on the endoscopy bed, the endoscopist explained how the test was done and asked if the patient had any further questions. Patients were then asked to read and sign the standard 'consent form for medical or dental investigation, treatment or operation' (Department of Health Consent Circular HSG(92)32), ${ }^{5}$ and underwent endoscopy immediately thereafter.

In the second 100 patients, a new endoscopy consent form (Figure), which was simpler and 
GUY'S HOSPITAL

DAY CASE SURGERY AND ENDOSCOPY UNIT IST FLOOR, NEW GUY'S HOUSE

\section{ENDOSCOPY CONSENT FORM}

\begin{tabular}{|c|c|c|}
\hline Patient's sumame & ..................................... & \\
\hline First name & 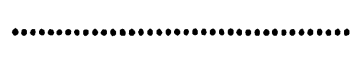 & Patient's Label \\
\hline Date of birth & 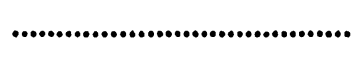 & \\
\hline Address................ & ............................................. & \\
\hline
\end{tabular}

1. Please read this consent form and the information sheet overleaf very casefully, and fill in your details above.

2. If there is anything that you don't understand about the endoscopy, or if you want more information, please do not sign the form yet. You will be able to discuss any worries or questions with the doctor before the endoscopy.

3. If you understand all the information you have been given, and have no further questions, then please sign below.

I agree to have an

ENDOSCOPY OF THE OESOPHAGUS, STOMACH AND DUODENUM

I understand 0 that I an choose between throat spray or an injection.

0 that the endoscopy will be done by a tained doctor from the Gastroenterology Unie.

- that 1 can ask the doctor any questions and seek further information. Having signed the consent form, I can still refuse the rest.

O that any procedure in addition to the endoscopy will only be carried out if it is necessary and in my best interests and can be justified for medical teasons.

Signature.

Date.

Please bring this form with you to the endoscopy room.

The new endoscopy consent form, sent out with an information sheet to patients two to four weeks before endoscopy, which could be signed at home if patients had no further questions about the test. clearly how the endoscopy would be done, while $20 \%$ denied receiving any explanation.

Ninety four per cent of patients had received and read the standard information sheet sent to them with the endoscopy booking. Overall, $97 \%$ found the sheet to be quite or very helpful in explaining how the endoscopy would be done. Twenty seven per cent, however, stated that they still wanted to ask questions of the endoscopist before the endoscopy.

Consent forms

Of the first 100 patients, all signed the standard consent form immediately before endoscopy, but only $54 \%$ had actually read the form before signing it.

In contrast, of the second 100 patients, the new form sent out with the information sheet was read by $95 \%$, and signed by $88 \%$, before coming to the unit. Furthermore, $84 \%$ found the new form easier to read and understand than the standard form, while $14 \%$ had no preference. Thirteen patients, none of whom had undergone an endoscopy before, and only one of whom had already signed the consent form, asked questions of the endoscopist, which related to the risks and side effects of endoscopy. Nine of 13 stated they had been given no explanation about the endoscopy by the referring doctor.

\section{Discussion}

This study has shown that, in our unit, the standard consent form issued by the NHS Management Executive ${ }^{5}$ is read by only about half of patients immediately before endoscopy. This may be partly because of the time constraints imposed by a busy endoscopy list, but it may also be that the form is often not read completely, or understood, because of its length and reading difficulty. Like the standard consent form used in this study, physicians tend to write information sheets, ${ }^{7}$ practice leaflets, ${ }^{6}$ and consent forms for research ${ }^{8}$ with a style of writing more closely related to articles in medical journals than to, for example, newspapers with the widest readership. ${ }^{8}$

The fact that the new endoscopy consent form sent out with the information sheet was read by $95 \%$ of patients, and was preferred to the standard form, suggests that there is a role for a specific endoscopy consent form, written in simple, lay language. Of the $12 \%$ of patients who had not signed the new consent form before arriving at the endoscopy unit, almost all asked further questions of the endoscopist, showing that this novel consent form signing procedure provided an additional safeguard against patients undergoing endoscopy without being fully informed. Furthermore, patients were able to read the form at home, and discuss it with others, at their leisure, a procedure that in other circumstances ${ }^{2}$ has been shown to improve knowledge and understanding in virtually every area required of informed consent.

In Britain, there have been very few studies of information requirements of patients undergoing endoscopy of the upper gastrointestinal
In the 200 patients ( 107 women, 93 men; mean age 50 years, range 19-85), the explanation of the indication for endoscopy by the referring doctor was perceived as clear in $79 \%$ of cases, but $15 \%$ of patients stated that no explanation had been given. Sixty eight per cent of patients stated that the referring doctor explained 
tract,,${ }^{10}$ and none on the issue of signed consent before endoscopy. This is surprising, given that endoscopic complications are responsible for most allegations of harm brought against gastroenterologists, and it behoves the endoscopist to ensure that patients are fully informed before endoscopy.

1 Editorial. Informed consent for gastrointestinal endoscopy. Gastrointest Endosc 1988; 34: 26-7S.

2 Morrow G, Gootnick J, Schmale A. A simple technique for increasing cancer patients' knowledge of informed consent to treatment Cancer 1978; 42: 793-9.

3 Lewis PJ, O'Keefe L, Adcock S. Patients who were given information sheets have better postoperative recall of information. $f R$ Coll Surg Edinb 1991 ; 36: 206-7.

4 Pereira SP, Hussaini SH, Hanson PJV, Wilkinson ML, Sladen GE. Endoscopy: throat spray or sedation? $\mathcal{F} R$ Coll Phys Lond 1994; 28: 41 1-4.

5 Delamothe T. Consenting patients. BMF 1990; 301: 510. 6 Albert T, Chadwick S. How readable are practice leaflets? $B M \mathcal{1}$ 1992; 305: 1266-8.

7 Smith T. Information for patients: writing simple English is difficult, even for doctors. BMF 1992; 305: 1242.

8 Priestley KA, Campbell C, Valentine CB, Denison DM, Buller NP. Are patient consent forms for research protocols easy to read? BMF 1992; 305: 1263-4.

9 Walker B, Smith MJ. Upper gastrointestinal endoscopy - a survey of patients' impressions. Postgrad Med f 1978; 54: survey

10 Probert CSJ, Jayanthi V, Quinn J, Mayberry JF. Information requirements and sedation preferences of patients undergoing endoscopy of the upper gastrointestinal tract. Endoscopy 1991; 23: 218-9. 